\title{
Forecast of Labor Force Supply in China from 2010 to 2050
}

\author{
WANG Wei ${ }^{1, a}$, ZHAO Jirong ${ }^{1, b}$ and YAO Yongzhi ${ }^{2, c^{*}}$ \\ ${ }^{1}$ School of Economics, Harbin University of Commerce, Harbin, P.R.China \\ ${ }^{2}$ School of Humanities and Social Science, Harbin Institute of Technology, Harbin, P.R.China \\ Awwww_1215@163.com, bzjr19891111@163.com, 'cyyz002@hit.edu.cn
}

Keywords: Labor supply; Population; Workforce; Age-specific; Forecast

\begin{abstract}
The labor supply is simulated in the study, including the level of death, the ratio of workforce, urban and rural labor supply, age-specific labor supply, and relevant results are forecast in China from 2010 to 2050 , by using the sixth census data, depending on the calculation of the basic population model, the prediction model of rural surplus labors, the urban economically active population model, and so on. In the current situation, the total workforce is in short supply and the pressure of provision for the aged increases continuously, the earlier the population policy is adjusted and the total fertility rate is enhanced, the more contributes will be made to solve the labor shortage problems in future.
\end{abstract}

\section{Introduction}

In 1987, National Bureau of Statistics calculated the number of surplus labor in rural areas by the method of per capita arable land, its results presents the agricultural sector needs 190 millions of labor, 80 million of the remaining. [1] Han Jun (2008) said, rural labor force is still oversupply currently in terms of quantity in China. At present, about 200 million had been transferred to the non-agricultural industry in 490 millions of the rural labor force. in the existing productivity, agricultural industry may need about 180 million of perennial labor, so the rural surplus labor force may be more than 100 million. [2] According to Chinese rural statistical yearbook, as of 2010, rural labor force has reached 468.75 million in China, at the same period the number of the rural workers was 242.23 million, including migrant workers 153.35 million, so the rural labor force of pure engaging in agricultural production presents 226.52 million in China. [3]

Gail Johnson has calculated the amount of transfer labor force in the future in China, referring to the measurement experience of studying other countries, through assuming that the speed of agricultural labor transfer to non-agricultural industries may be $3 \%$ each year, so that the agricultural labor force will be about 103 million by 2030 , which will drop to about $10 \%$ of total employment, is equivalent to Japan's in 1980.[4],[5]

In combination with the simulation experiment system of Chinese Academy of Labor and Social Security, through adopting the sixth census data, and on basis of the calculation and analysis of the basic population model, the prediction model of rural surplus labors, the urban economically active population model and so on,[6],[7] the labor supply data of China from 2010 to 2050 is simulated and relevant results are drawn, and the paper analyzes the labor supply condition of China in the next 40 years from the aspects of the total quantity, the urban and rural area, the age, etc.

\section{Forecast of Level of Death from 2010 to 2050}

Initial population data in 2010 is based on the sixth census.[8] Fertility levels, total fertility rate, TFR, are divided into three types, including $1.5,1.7$ and 1.9, will be analyzed respectively in this paper. Urban and rural migration level, urbanization rate, is calculated by the method of linear difference by taking the actual data in 2010 as the initial level, wherein the value of 2050 is $80 \%$.

The related parameters in the simulation system are as Table 1. 
Table 1 Level of death based on life expectancy

\begin{tabular}{|r|r|r|r|r|r|r|r|r|r|r|}
\hline Year & $\mathbf{2 0 1 0}$ & $\mathbf{2 0 1 1}$ & $\mathbf{2 0 1 2}$ & $\mathbf{2 0 1 3}$ & $\mathbf{2 0 1 4}$ & $\mathbf{2 0 1 5}$ & $\mathbf{2 0 1 6}$ & $\mathbf{2 0 1 7}$ & $\mathbf{2 0 1 8}$ & $\mathbf{2 0 1 9}$ \\
\hline Male & 72.1 & 72.1 & 72.1 & 72.1 & 73 & 73 & 73 & 73 & 73 & 73 \\
\hline Female & 75.6 & 75.6 & 75.6 & 75.6 & 76.7 & 76.7 & 76.7 & 76.7 & 76.7 & 76.7 \\
\hline Year & $\mathbf{2 0 2 0}$ & $\mathbf{2 0 2 1}$ & $\mathbf{2 0 2 2}$ & $\mathbf{2 0 2 3}$ & $\mathbf{2 0 2 4}$ & $\mathbf{2 0 2 5}$ & $\mathbf{2 0 2 6}$ & $\mathbf{2 0 2 7}$ & $\mathbf{2 0 2 8}$ & $\mathbf{2 0 2 9}$ \\
\hline Male & 73.8 & 73.8 & 73.8 & 73.8 & 73.8 & 74.6 & 74.6 & 74.6 & 74.6 & 74.6 \\
\hline Female & 77.6 & 77.6 & 77.6 & 77.6 & 77.6 & 78.4 & 78.4 & 78.4 & 78.4 & 78.4 \\
\hline Year & $\mathbf{2 0 3 0}$ & $\mathbf{2 0 3 1}$ & $\mathbf{2 0 3 2}$ & $\mathbf{2 0 3 3}$ & $\mathbf{2 0 3 4}$ & $\mathbf{2 0 3 5}$ & $\mathbf{2 0 3 6}$ & $\mathbf{2 0 3 7}$ & $\mathbf{2 0 3 8}$ & $\mathbf{2 0 3 9}$ \\
\hline Male & 75.3 & 75.3 & 75.3 & 75.3 & 75.3 & 76 & 76 & 76 & 76 & 76 \\
\hline Female & 79.2 & 79.2 & 79.2 & 79.2 & 79.2 & 79.9 & 79.9 & 79.9 & 79.9 & 79.9 \\
\hline Year & $\mathbf{2 0 4 0}$ & $\mathbf{2 0 4 1}$ & $\mathbf{2 0 4 2}$ & $\mathbf{2 0 4 3}$ & $\mathbf{2 0 4 4}$ & $\mathbf{2 0 4 5}$ & $\mathbf{2 0 4 6}$ & $\mathbf{2 0 4 8}$ & $\mathbf{2 0 4 9}$ & $\mathbf{2 0 5 0}$ \\
\hline Male & 76.6 & 76.6 & 76.6 & 76.6 & 76.6 & 77.3 & 77.3 & 77.3 & 77.3 & 77.3 \\
\hline Female & 80.6 & 80.6 & 80.6 & 80.6 & 80.6 & 81.2 & 81.2 & 81.2 & 81.2 & 81.2 \\
\hline
\end{tabular}

\section{Forecast of the Ratio of Workforce of the Total Population}

According to the sixth national population census data, the total labor force population of China between 16 and 64 years old is 974.786093 million in 2010, which accounts for about $73 \%$ of the total population of the state,[9] based on the data and related parameters setting, the total labor force of China between 16 and 64 years old between 2010 and 2050 predicted by the simulation system is as shown in Fig .1.

We can see from the Fig .1, no matter which total fertility rate the calculation is based on, the total labor force of China between 16 and 64 years old is a downward trend as a whole, wherein the total labor force from 2010 to 2013 is still slightly increased, the number is 983.954090 million in 2013, but the data begins to decline till 2050 and there is little volatility during which excepting for the different between falling speed due to the set of total fertility rate. According to the trend shown in Fig .2, the growth rate of the total labor force turns to be negative since 2014, and the change after that is only the decreasing speed of labors.

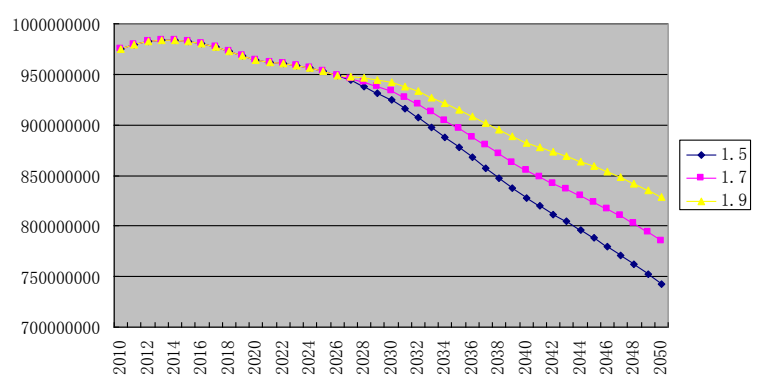

Figure. 1 The change tendency of the total population between 16 and 64 years old under different total fertility rate

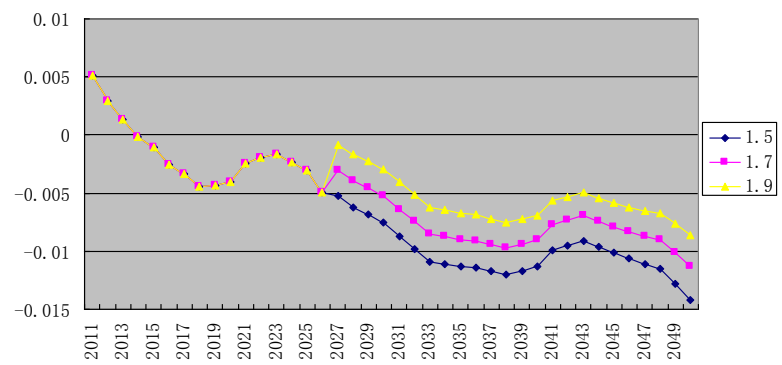

Figure. 2 Annual Increasing Rate of the Population between 16 and 64 Years Old under Different Total Fertility Rate 
According to different settings of the total fertility rate, although the total fertility rates from 2010 to 2026 are different, the total workforce under the three conditions has no difference, the reasons for this situation is that if the total fertility rate is adjusted in 2010, since the labors, that is, the population from 16 to 64 years old, entering the rank of labor force population before 2026 were born before 2010, the adjustment of the total fertility rate has no effect to this part of people. Since 2027, the population affected by the adjustment of the total fertility rate just over the age of 16 and enters the rank of labor force population, whereas, the total workforce begins to change along with different total fertility rate and the difference is bigger and bigger, therefore, in 2050, the total workforce under three total fertility rates are 742.058471 million, 785.196772 million, 828.564363 million in respective, and the influences of the total fertility rate on the labor supply can be fully released till 2075 in Figure 3. It also shows that the time lag exists in the influence of the adjustment to the total fertility rate on the quantity of labor forces, so that should be considered in policy making.

In addition, viewing from the proportion of people between 16 and 64 years old to the total population, this proportion is a downward trend from 2010 to 2010 and the higher the total fertility rate is, the lower the proportion will be.

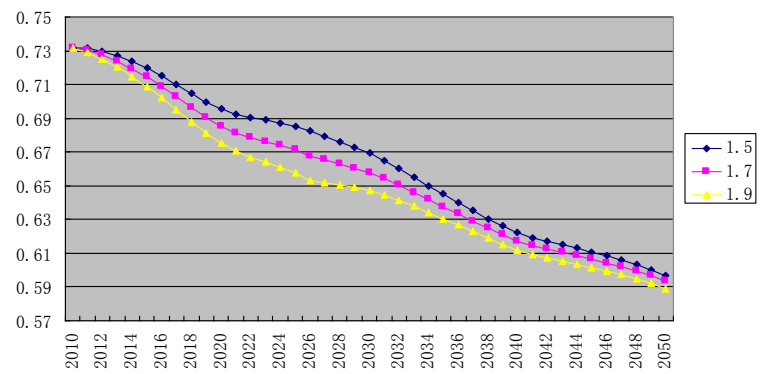

Figure. 3 The change tendency of the proportion of people between 16 and 64 years old to the total population under different total fertility rate

\section{Forecast of Urban and Rural Labor Supply Situation}

Divided into urban and rural, the evolution trends of the labor force population in urban and rural are quite different.[10] In the urban area, as shown in Fig .4, whatever the total fertility rate is, the overall trend of the total workforce is fall after rise, the differences between different total fertility rates are embodied in two aspects. Firstly, the lower the total fertility rate, the less the workforce, this judgment only applies to the situation after 2026 because the total fertility rate has no influence on the labor supply quantity before 2026 and the reason has been explained herein before, in 2050, the total workforce in urban area under three total fertility rates are respectively 628.559001 million, 662.575821 million and 697.002422 million, therefore, the differences are very significant. Secondly, the lower the total fertility rate, the earlier the peak of the total workforce comes; it can be seen from the figure that when the total fertility rate is 1.5 , the peak of the total urban workforce appears in 2043, 639.963768 million, when the total fertility rate is 1.7 , the peak of the total urban workforce appears in 2047, 665.886718 million, when the total fertility rate is 1.9, the peak of the total urban workforce up to 2050 appears in $2049,697.055579$ million, and seeing from the trend, the data will also enter the decline phase after 2050.

The situation of the rural area is shown in Fig .5. The situation of the rural labor force supply is relatively simple, viewing from a general trend, the total rural workforce will be a downward trend, and the differences under different total fertility rates are slightly, which is associated with the rapid urbanization process of China. 


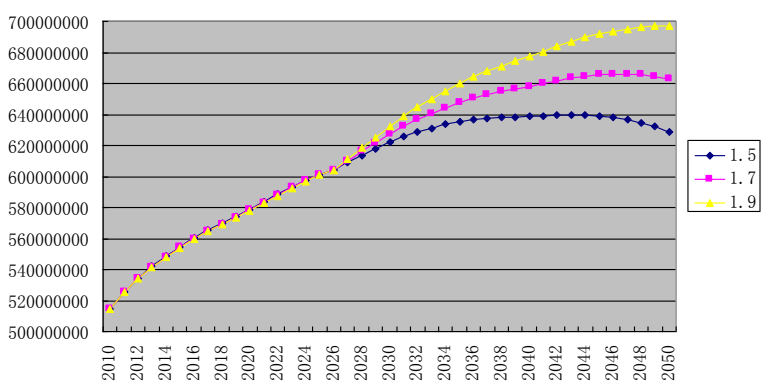

Figure. 4 The change tendency of the urban population between 16 and 64 years old under different total fertility rate

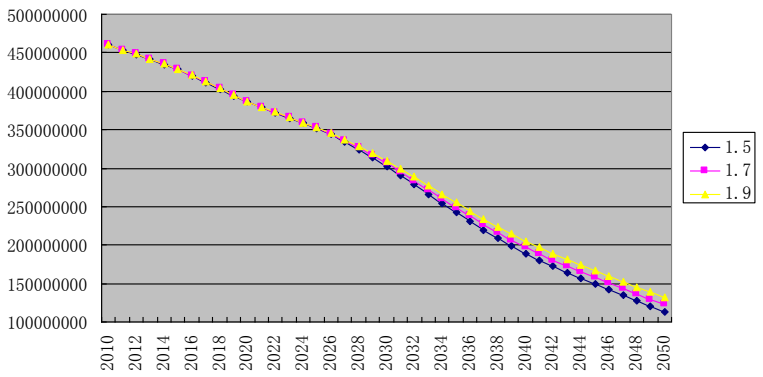

Figure. 5 The change tendency of the rural population between 16 and 64 years old under different total fertility rate

\section{Forecast of Age-specific labor supply conditions}

In the condition that the total fertility rate is 1.5 , the aging trend of the age structure in China is obvious. In 2010, the population of the two age groups including 20 to 25 years old and 40 to 45 years old will account for the biggest proportion of the whole age structure, they will provide a relatively plenty of young adults workforce to our country, however, as time goes on, all of them will be out of the rank of workforce or dead in 2050, and the quantity added into the rank of workforce is less and less, so that the population pyramid will present a serious inverted pyramid status.[11]

Compared with the total fertility rate of 1.5 , the condition under the total fertility rate of 1.7 is slightly better, although the aging situation is still serious by 2050 , the number of population newly added into the rank of workforce is also large, so that the entire population pyramid is developed towards the direction of a columnar and the labor forces of all ages are quite uniform.
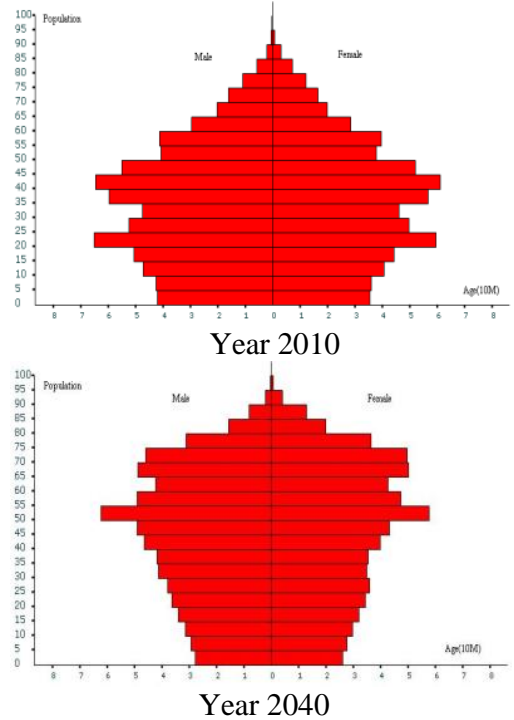
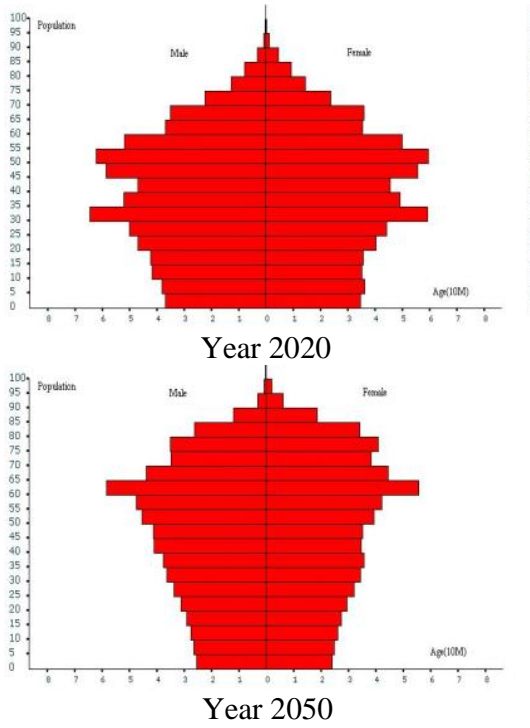

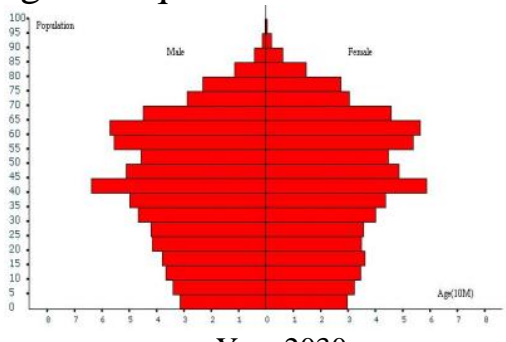

Year 2030

Figure. 6 The Population Age Structure between 2010 and 2050 with the Total Fertility Rate of 1.5 


\section{Conclusion}

Firstly, by 2050, the decline of the total labor force is an inevitable trend, but the pace and the overall amplitude of decline are bounded with the trend of the population policy adjustment, in the current condition that the total workforce is in short supply and the pressure of provision for the aged increases continuously, the earlier the population policy is adjusted and the total fertility rate is enhanced, the more contributes it makes to solve the labor shortage problems in future.

Secondly, because of the influence of urbanization on the urban and rural labor forces supply, the rural labor forces will decline continuously while the urban labor forces will rise to a peak and then start to decline, where in the time and amplitude of the peak varies according to different total fertility rates of the population. Viewing from the policy implications of data, how to ensure that there are plenty of workforce in the rural area, how to balance the relationship between the demand for labors and the carrying capacity of urban public services in the rapid urbanization process and other problems should be taken into consideration.

Thirdly, the trend of inverted-pyramid-like age structure of workforce is significant, the quantity of youth labor forces as a whole is a downward trend while the 61-64 years old population and the proportion thereof to the total population climb constantly. Viewing from the policy perspective, under the current background of the aging tendency of population, it is considerable to supplement youth labors with 61-64 years old people to ease the problem of labor famine.

\section{Acknowledgment}

This work is partially supported by the Humanities and Social Sciences Fund of Ministry of Education under Grant 12YJC790190, the young academic backbone support program under Grant 1253G029 in Heilongjiang Province, SSFC under Grant 13AZD071, National Soft Science Research Project under Grant 2013GXS2D020 in China, and Postdoctoral Scientific Research Initiation Grant LBH-Q14094, the Soft Science Technology Foundation under Grant GC13D101, QC07C117 in Heilongjiang Province in China.

\section{References}

[1] Chen Jiyuan, On agricultural surplus labor transfer, the route of agricultural modernization must take in China, Economic Management Press, Beijing, 1991, pp.143-145.

[2] Han Jun, 30 years of China economic reform focusing on the rural economy from 1978 to 2008, Chongqing University Press, Chongqing, 2008, pp.170-171.

[3] Thomas Rawski, On the Number of Agricultural Labor Force in China, China Rural Survey, 4 (1997) 28- 39 .

[4] Fengyun Hou, Empirical Analysis on the Surplus Scale and Mobility Scale of Rural Labor Force in China. China Rural Economy, 3 (2004) 13- 21.

[5] Wang Wei, Chen Funing, Wang Zhihao, Liu Chang, On the Employment States of Three Major Industries in Each Region of Harbin in China in 2010, Information Technology Journal, 12(21), (2013) 6359-6362.

[6] Lixia Yang, Guishan Yang, Shaofeng Yuan, Mathematical Models in Population Prediction, for Example as Jiangsu Province, Changsha Resources and Environment, 15(3), (2006) 288-290.

[7] Ruijuan Wang, Actively Exploring New Ways of Surplus Labor Transfer in China, Theoretical Study, 1 (2004) 5- 7.

[8] National Bureau of Statistics, China Statistical Yearbook, China Statistics Press, Beijing, ( 2010) 
[9] Wang Wei, Qu Weishuang, Wang Zhihao, Liu Chang, Estimation and Forecast of the Agricultural Surplus Labor Force in China from 2012 to 2040, Journal of Applied Sciences, 13(12), (2013) 3921-3925.

[10] Jianjin Liu, Transfer of Rural Labor and Non-formal Employment Opportunities, Economic Information Daily, December 24 (2003)

[11]Lianzhong Li, Age Structure and Gender-specific Population Growth Mode, Journal of Xuzhou Normal University (Natural Science), 26(2), (2008) 124-127. 